old to be bothered', 'worriers', 'fatalists' and 'avoiders'. Declining patients perceived they were at low risk compared to those taking part. Risk was believed to be related to family history and current health rather than smoking.

Conclusion Whilst screening methods in the Lung-SEARCH trial are largely acceptable to trial participants, strategies to increase acceptability and participation of this at-risk group should include providing tests locally, resolving anxieties concerning screening tests and addressing beliefs of those who underestimate or deny their risk of lung cancer.

\section{P213 LONG TERM RESULTS OF CONCURRENT CHEMOTHERAPY AND HYPOFRACTIONATED RADIOTHERAPY FOR INOPERABLE NSCLC}

doi:10.1136/thx.2010.151068.14

J Maguire, V Kelly, C Smyth, M Ledson, M Walshaw. Liverpool Heart and Chest Hospital, Liverpool, UK

Concurrent chemoradiation is an effective form of treatment for inoperable stage 3 NSCLC, with a survival advantage in metaanalyses compared to standard chemotherapy and radiotherapy. However, reported local tumour control (LTC) rates are less than $40 \%$. US studies aim to improve LTC by radiotherapy dose escalation and the addition of cetuximab. An alternative approach is to deliver radical radiotherapy concurrent with chemotherapy within a 4-week period, aiming to minimise the effects of accelerated repopulation and thus enhance LTC and survival.

We have treated 104 NSCLC patients with cisplatinum (30 patients) or cisplatinum and vinorelbine (74 patients) concurrently with 50-55Gy in 20 fractions over 26 days. Two-thirds of the patients were male, one third female; median age was 64. 90 patients had stage 3 NSCLC, 12 patients had inoperable stage 2 disease, and 2 had stage 4 disease. 84 patients were PS 0-1, 18 PS 2 and 2 PS 3. 64 patients received between two and four cycles of chemotherapy after completion of concurrent treatment.

Median survival for the whole group was 23 months. Survival rates at 3,5 and 10 years (all causes mortality) were $41.7 \%, 30.1 \%$ and $16.2 \%$. Chemotherapy after concurrent treatment increased median survival (26.6 vs 14.6 months) and survival at 2 years $(53.1 \%$ vs $40 \%$ ) but made no difference to survival at three and 5 years. There was an advantage for patients who received 55Gy compared to those who received 50-52.5Gy, with median survival of 37.9 months versus 20.6 months, 2 -year survival $64.2 \%$ versus $40 \%$, 3 -year survival $56.2 \%$ versus $34.2 \%$ and 5 -year survival $36 \%$ versus $28.5 \%$. The local tumour control rate was $76 \%$ for patients receiving $55 \mathrm{~Gy}$ and $68.6 \%$ for patients receiving $50-52.5 \mathrm{~Gy}$.

There were no treatment related deaths. 86 patients developed grade 2 oesophagitis, nine patients suffered grade 3 oesophagitis and eight patients required dilation of oesophageal stricture between 8 weeks and 3 years after treatment.

Chemoradiation usingaccelerated hypofractionated radiotherapy concurrent with cisplatinum and vinorelbine enhances local control and survival for patients with locally advanced NSCLC and good performance status.

\section{P214 PATHOLOGICAL STAGING OF MALIGNANT PLEURAL MESOTHELIOMA. HOW IMPORTANT IS NODAL DISEASE IN SELECTION FOR RADICAL SURGERY?}

doi:10.1136/thx.2010.151068.15

A Nakas, K Lau, D Waller. Glenfield Hospital, Leicester, UK

Purpose Selection criteria for radical surgery in malignant pleural Mesothelioma (MPM) and related clinical trials remain contro- versial. The relative importance of nodal metastases and the need for preoperative nodal staging are undetermined.

Methods From a prospective database, we identified 203 patients (175 male and 28 female) with non-sarcomatoid MPM (Epithelioid 154 patients; Biphasic 49 patients). Preoperative staging included CT and mediastinoscopy. We investigated the effect of nodal burden and distribution on overall survival.

Results 125 patients underwent extrapleural pneumonectomy (EPP) and 78 radical pleurectomy/decortication (RPD) all with systematic nodal dissection. There was no difference in survival between EPP or RPD: 1 year $63 \%$ vs $56 \%$; 3 year $17 \%$ vs $15 \%$ and 5 year $8 \%$ vs $5 \%$ $\mathrm{p}=0.55$. The median number of lymph nodes resected was $10(1-58)$; $88(43 \%)$ patients were N0, 18 (9\%) N1 and 97 (48\%) N2. Patients with N0 disease had the best prognosis: median survival 22 months (SE 3, 95\% CI 16 to 28) versus 11 months (SE 3, 95\% CI 4 to 18) for N1 and 14 months (SE $1,95 \%$ CI 11 to 17) for $\mathrm{N} 2, \mathrm{p}=0.005$. There was no significant survival difference between $\mathrm{N} 1$ and $\mathrm{N} 2, \mathrm{p}=0.85$. Overall survival was associated with the absolute number of positive extrapleural lymph nodes $(p=0.05)$ and the number of extrapleural nodal stations involved $(p=0.01)$ but not, the total (intra and extra pleural) number of involved nodes or stations ( $p=0.13$ and 0.23 ).

Conclusions Extrapleural nodal status remains one of the most important prognostic factors following radical surgery for malignant pleural Mesothelioma. These data have important implications for preoperative staging and revision to the current IMIG staging system.

Abstract P214 Table 1 Actuarial survival following radical surgery

\begin{tabular}{llllll}
\hline $\begin{array}{l}\text { EPP + RPD } \\
\mathbf{n}=\mathbf{2 0 3}\end{array}$ & $\begin{array}{l}\mathbf{1} \text { year } \\
\text { survival }\end{array}$ & $\begin{array}{l}\text { 2 years } \\
\text { survival }\end{array}$ & $\begin{array}{l}\mathbf{3} \text { years } \\
\text { survival }\end{array}$ & $\begin{array}{l}\mathbf{4} \text { years } \\
\text { survival }\end{array}$ & $\begin{array}{l}\mathbf{5} \text { years } \\
\text { survival }\end{array}$ \\
\hline $\mathrm{pN} 0 \mathrm{n}=88$ & $70 \%$ & $46 \%$ & $23 \%$ & $17 \%$ & $15 \%$ \\
$\mathrm{pN} 1 \mathrm{n}=18$ & $44 \%$ & $22 \%$ & $7 \%$ & - & - \\
$\mathrm{pN} 2 \mathrm{n}=97$ & $55 \%$ & $22 \%$ & $10 \%$ & $7 \%$ & - \\
\hline
\end{tabular}

\section{P215 THE INFLUENCE OF AGE ON MANAGEMENT OF LUNG CANCER PATIENTS IN ENGLAND}

doi:10.1136/thx.2010.151068.16

${ }^{1} \mathrm{P}$ Beckett, ${ }^{1}$ I Woolhouse, ${ }^{1} \mathrm{M}$ D Peake, ${ }^{2} \mathrm{R}$ Stanley, ${ }^{3} \mathrm{R} \mathrm{N}$ Harrison. ${ }^{1}$ Royal College of Physicians, London, UK; ${ }^{2}$ The Information Centre for health and social care, Leeds, UK; ${ }^{3}$ North Tees University Hospital, Stockton-on-Tees, UK

Introduction The evidence on which to base treatment decisions in the elderly patient with lung cancer is generally considered to be inadequate, with significant under-representation of older patients in key clinical trials. Although European recommendations have recently been published confirming the benefits of active treatment (EORTC Elderly Task Force), there are no UK guidelines and anecdotal evidence suggests that in the UK elderly patients have much lower rates of active treatment for lung cancer.

Methods Using the National Lung Cancer Audit dataset of 27815 patients first seen in 2008, we have analysed a variety of measures according to patient age at the time of diagnosis. Patients outside the range 38-96 were excluded due to low numbers.

Results Comparison with Cancer Research-UK data shows that the elderly are not under-represented in the dataset; neither is there any evidence of under-reporting of key case-mix variables such as PS and Stage. Older patients tend to have lower stage at diagnosis, but this may be due to a reduced intensity of investigations. Not unexpectedly, there is a rapid decline in the proportion with good PS after age 70. Whilst $\mathrm{FEV}_{1}$ (absolute) declines with age, the average $\mathrm{FEV}_{1} \%$ 
of predicted remains quite constant at around $70 \%$. There is an increase in recording of co-morbidities from around $5 \%$ in young patients to around $20 \%$ in the very elderly. There is a clear and dramatic fall in a number of measures of process and treatment such as histological confirmation rate, anti-cancer treatment, and chemotherapy use beginning around the 7 th decade of life. The histological confirmation rate falls from $75 \%$ at age 65 to $40 \%$ at age 85 - the corresponding rates for specific anti-cancer therapy are $65 \%$ and $25 \%$. More concerning is the finding that these variations persist when corrected for PS and co-morbidities (see Abstract P215 Figure 1 ), with treatment rates falling from $50 \%$ to $4 \%$.

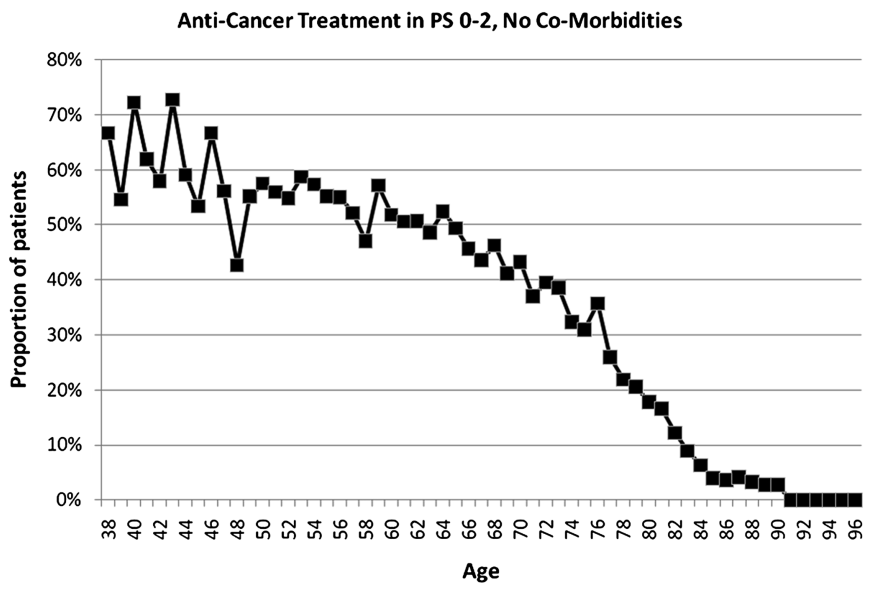

Abstract P215 Figure 1 Anti-Cancer treatment in PS 0-2, no comorbidities

Conclusions Age appears to be an important factor in management decisions in English lung cancer practice. The results indicate that further work is warranted to determine how far the results can be explained by patient preference, appropriate physician judgement and physician prejudice.

\section{P216 LUNG CANCER IN YOUNG PATIENTS: A RETROSPECTIVE STUDY}

doi:10.1136/thx.2010.151068.17

Rahuldeb Sarkar, Gareth Jones, Tania Peacock, Ana de Ramón Casado. Warrington Hospital, Warrington, UK

Introduction Over-representation of women, more advanced disease staging at presentation, better performance status and similar survival figures have been noticed in younger ( $<50$ years) lung cancer patients as compared to the general patient population with the disease.

Objective A retrospective study (December 2009) was done to derive clinicopathological data from young lung cancer patients treated in our hospital in the last 5 years. We also compared our findings with National Lung Cancer Audit (NLCA), 2007 in the UK. The NLCA data were considered as a reflector of the patients from all age groups.

Findings 28 patients were identified for the study. Median age was 48 years (37-50). 15(54\%) were female. $75 \%$ had WHO performance status (PS) 1 in patients with documented PS. $43 \%$ had family history of lung cancer. $89 \%$ were current smoker. Histology was achieved in $89 \%$. 68\% had non small cell carcinoma (NSCLC) including 39\% adeno carcinoma, $24 \%$ had small cell carcinoma; 2 had carcinoid. $55 \%$ of histology proven NSCLC had stage 4 disease at presentation. $86 \%$ had some form of treatment (surgery, chemotherapy or radiotherapy). 5(18\%) had resection. Survival related data are presented here:

\begin{tabular}{lll}
\hline & Median survival (days) & 1 year survival rate (\%) \\
\hline All patients & 254 & 32 \\
Male & 193 & 25 \\
Female & 261 & 36 \\
\hline
\end{tabular}

Comparison between our findings and the NLCA data are presented below [Abstract P216 Table 1].

\section{Abstract P216 Table 1}

\begin{tabular}{lll}
\hline & NLCA data & Local data \\
\hline Male:female & $1.4: 1$ & $0.86: 1$ \\
Histological confirmation & $68 \%$ & $89 \%$ \\
$\begin{array}{l}\text { Stage IV at presentation } \\
\text { in NSCLC }\end{array}$ & $32 \%$ & $55 \%$ \\
$\begin{array}{l}\text { Active treatment } \\
\text { received }\end{array}$ & $51 \%$ & $86 \%$ \\
$\begin{array}{l}\text { Resection in NSCLC } \\
\text { Median NSCLC survival }\end{array}$ & $14 \%$ & $17 \%$ \\
(day) & 232 & 246 \\
\hline
\end{tabular}

Conclusion Majority of these patients presented with advanced stage disease as in previously reported larger cohorts. Women were a majority but they had a better survival than men. $43 \%$ had positive family history suggesting a possible genetic factor. A good proportion in this patient group had favourable performance status resulting in higher resection rate and receiving of active treatment compared to overall patient population. However, this did not lead to better survival.

\section{P217 WHAT'S HAPPENING TO LUNG CANCER IN FEMALES?}

doi:10.1136/thx.2010.151068.18

A Ives, J Verne. South West Public Health Observatory, Bristol, UK

Aim To examine trends in female lung cancer incidence.

Introduction Lung cancer incidence in men has been decreasing for the past 2-3 decades, while for females it has increased. Furthermore, to achieve the national cancer mortality target reduction, it is essential that lung cancer incidence reduces as this is a major contributor to the mortality target. Mortality trends closely mirror that of incidence due to the poor prognosis of lung cancer.

Methodology The UK Association of Cancer Registries dataset was used to identify female lung cancer cases diagnosed between 1985 and 2006 in England and its constituent Regions. Three year rolling directly age-standardised rates (standardised to the European population) was calculated. National deprivation quintiles were used, where deprivation was based on the income domain of Indices of Multiple Deprivation 2007. The postcode of residence of each patient was used to assign the relevant deprivation quintile.

Results England lung cancer incidence for females significantly increased $(p<0.01)$ from 1985 to 1987 (32.3 per 100000) and 2004-2006 (35.4 per 100000$)$. Incidence and trends across Regions varies significantly. Further analysis at Network/LA level shows even more extreme variation in trends. By 2030, it is anticipated that lung cancer incidence will be similar for both males and females in the South West Region. In the past 20 years the inequalities gap for females is widening. Incidence rates have increased in the most deprived population $(30 \%)$ of the South West, while remaining relatively stable in the most affluent population of the region. Each Region shows different inequalities. 